\title{
Mineração
}

\section{Oxidação de sulfetos de níquel com microorganismos mesófilos}

\author{
(Nickel sulphide oxidation by mesophile bacteria)
}

Luciano Rodrigo Gomes Santos

Núcleo de Valorização de Materiais Minerais/DEMET/UFOP, E-mail: lucianoufop@yahoo.com.br

Alexandre Ferraz Barbosa

Núcleo de Valorização de Materiais Minerais/DEMET/UFOP, E-mail: ferraz27@bol.com.br

Adelson Dias Souza

Votorantim Metais - Desenvolvimento tecnológico.Email: adelson@vmetais.com.br

Versiane Albis Leão

Núcleo de Valorização de Materiais Minerais/DEMET/UFOP, E-mail: versiane@demet.em.ufop.br

\section{Resumo}

A oxidação de sulfetos metálicos tem sido associada à drenagem ácida de mina, um dos maiores problemas ambientais na mineração. Uma das formas de se acelerar a oxidação desses sulfetos é a biolixivação, na qual o crescimento desses microorganismos é favorecido. Foi estudada, nesse trabalho, a oxidação de um concentrado sulfetado complexo de pentlandita/pirrotita utilizando bactérias mesófilas. Foram avaliados os efeitos do $\mathrm{pH}$ e do percentual de sólidos sobre a extração do níquel. Os resultados indicaram que a biolixiviação pode ser uma alternativa viável ao processamento de sulfetos complexos de ferro e de níquel, uma vez que foram obtidos percentuais de extração acima de $60 \%$. O pH possui pequena influência nos percentuais de extração obtidos, sendo o valor ideal igual a 2,0. Sua influência parece estar ligada, principalmente, à regulação da atividade bacteriana. Percentuais de sólidos elevados (aproximadamente de 10\%) podem ser praticados, sem apresentarem diferenças significativas na extração final de níquel, pois a transferência gasosa no sistema é pouco comprometida. Dessa forma, o fator limitante da atividade bacteriana, em percentuais elevados de sólidos, é a disponibilidade de dióxido de carbono.

Palavras-chave: Oxidação, concentrados de níquel, pentlandita.

\begin{abstract}
Metallic sulphide oxidation has been associated to the generation of acid mine drainage, one of the most import environmental issues in the mining industry. Bioleaching can be applied to accelerate sulphide oxidation, ceasing these impacts. This work sought to study the biooxidation of a complex nickel-iron sulphide (pentlandite and pyrrhotite) using acidophile ironoxidizing bacteria. The effects of $\mathrm{pH}$ and solids concentration on the extraction of nickel were evaluated. A high nickel extraction (around 60\%) can be achieved confirming the feasibility of nickel sulphide bioleaching. The $\mathrm{pH}$ has a negligible effect on nickel extraction being $\mathrm{pH} 2.0$ the best value. Nickel dissolution can be achieved at high solid percentages since gaseous transfer in the system is not strongly affected. It is suggested therefore that sulphide dissolution under these conditions is limited by the availability of carbon dioxide in the leaching system, which controls bacterial growth.
\end{abstract}

Keywords: Biooxidation, nickel sulphides, pentlandita. 


\section{Introdução}

A oxidação de sulfetos metálicos tem sido associada à drenagem ácida de mina (DAM), um dos maiores problemas ambientais na mineração. Entre esses materiais, destacam-se os sulfetos complexos, que são caracterizados pelo fino intercrescimento dos grãos de duas ou mais espécies minerais, o que torna o comportamento desses sistemas de difícil previsão devida à efeitos galvânicos (Gómez et al., 1999).

A bioxidação de sulfetos metálicos é devida, principalmente, à habilidade de bactérias acidofílicas de oxidar Fe(II) e/ ou compostos sulfetados (Lacey \& Lawson, 1970). Apesar de apresentar cinética mais lenta que a dos processos químicos de oxidação de sulfetos à pressão ambiente, a bioxidação natural é de difícil controle. Nesse caso, uma das formas de se acelerar a oxidação desses sulfetos é a biolixiviação, na qual o crescimento desses microorganismos é favorecido. A biolixiviação é considerada uma opção de baixo custo, ideal para o processamento de minérios marginais complexos e de rejeitos (Daman et al., 2002).

Entre os microorganismos empregados na biolixiviação, existem, basicamente, dois grupos: os oxidantes de $\mathrm{Fe}(\mathrm{II})$ e os que oxidam formas reduzidas de enxofre (Garcia Jr., 1991). Esses microorganismos definem os dois tipos de mecanismos que atuam durante a biolixiviação de sulfetos metálicos. O primeiro é denominado mecanismo direto, no qual o microorganismo, aderido à superfície do mineral, realiza a dissolução do mesmo, por meio de reações enzimáticas (Sand et al., 2001). Quando ocorre a formação de enxofre elementar, que age como uma barreira para a difusão do agente oxidante até a superfície do mineral, alguns microorganismos (oxidantes de enxofre) atuam na oxidação deste último. Esse fenômeno é conhecido como mecanismo direto (Fowler \& Crundwell, 1999).

O segundo mecanismo é denominado mecanismo indireto. Nele, o mineral é atacado, quimicamente, pelo íon Fe(III) e/ou por prótons $\left(\mathrm{H}^{+}\right)$presentes na solução, dependendo da configuração eletrônica do sulfeto. Durante a oxidação química do mineral, o Fe(III) é transformado em Fe(II). A função do microorganismo, neste caso, é reoxidar $\mathrm{Fe}(\mathrm{II})$ a $\mathrm{Fe}(\mathrm{III})$, regenerando o agente oxidante.

As reações propostas para a biolixiviação da pentlandita são (McIntosh \& Groat, 1997):

Mecanismo direto:

$8(\mathrm{Ni}, \mathrm{Fe})_{9} \mathrm{~S}_{8(\mathrm{~s})}+141 \mathrm{O}_{2(\mathrm{~g})}+26 \mathrm{H}_{2} \mathrm{SO}_{4} \rightarrow 36 \mathrm{NiSO}_{4(\mathrm{aq})}+18 \mathrm{Fe}_{2}\left(\mathrm{SO}_{4}\right)_{3(\mathrm{aq})}+26 \mathrm{H}_{2} \mathrm{O}$

Mecanismo indireto:

$(\mathrm{Ni}, \mathrm{Fe})_{9} \mathrm{~S}_{8(\mathrm{~s})}+9 \mathrm{Fe}_{2}\left(\mathrm{SO}_{4}\right)_{3(\mathrm{aq})} \rightarrow 9 \mathrm{NiSO}_{4(\mathrm{aq})}+18 \mathrm{FeSO}_{4(\mathrm{aq})}+8 \mathrm{~S}^{0}(\mathrm{~s})$

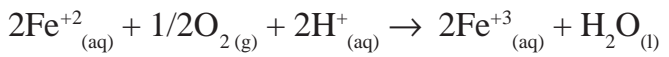

$\mathrm{S}_{(\mathrm{s})}^{0}+3 / 2 \mathrm{O}_{2(\mathrm{~g})}+\mathrm{H}_{2} \mathrm{O}_{(\mathrm{l})} \rightarrow \mathrm{H}_{2} \mathrm{SO}_{4(\mathrm{aq})}$

Nesse trabalho, é discutida a influência do pH e do percentual de sólidos na biolixiviação de um concentrado sulfetado complexo de níquel, utilizando uma cultura mista de microorganismos mesófilos (Acidithiobacillus sp.).

\section{Materiais e Métodos}

Utilizou-se, nesse trabalho, um concentrado complexo de sulfeto de níquel (pentlandita), contendo alto teor de ferro, gentilmente cedido pela Votorantim Metais. Esse concentrado era utilizado na alimentação do forno "Flash Smelter" da usina de Fortaleza de Minas, do mesmo grupo.

A caracterização mineralógica foi realizada antes dos ensaios de biolixiviação, utilizando difração de raios X em um equipamento Shimadzu-XRD6000, seguida de caracterização ao microscópio óptico Leicca DMLP e ao microscópio eletrônico de varredura (MEV) (modelo JEOL JSM 501), combinado a um sistema de análise elementar semiquantitativo de energia dispersiva de raios-X (EDS). A análise de área superficial foi realizada em um equipamento "High Speed Gaz Sorption Analyzer", modelo Nova 1000, marca Quantachrome.

Para o estudo das variáveis que afetam a extração de níquel, utilizaram-se bactérias previamente adaptadas, por 12 semanas, em um reator de 10L, contendo meio de cultivo, em pH igual a 1,8, com 5\% de sólidos e em condições ótimas de aeração. Os inóculos utilizados em todos os ensaios de biolixiviação do concentrado de pentlandita foram retirados dessa cultura.

Os ensaios de biolixiviação foram conduzidos em erlenmeyers de $250 \mathrm{~mL}$, dispostos em agitadores orbitais a $200 \mathrm{~min}^{-1} \mathrm{e}$ à temperatura de $34^{\circ} \mathrm{C}$. Esse sistema era inoculado com $10 \mathrm{~mL}$ de solução contendo aproximadamente $10^{8} \mathrm{bact} / \mathrm{mL}$. Utilizouse, nos experimentos, um percentual de sólidos igual a 5\%, com exceção dos ensaios em que o percentual de sólidos era a variável estudada. Ensaios-controle foram conduzidos na presença de timol.

Para crescimento da cultura de Acidithiobacillus sp., utilizou-se o meio Norris, contendo 0,2g/L de $\left(\mathrm{NH}_{4}\right) \mathrm{SO}_{4}$ 0,4g/L de $\mathrm{MgSO}_{4} .7 \mathrm{H}_{2} \mathrm{O}$ e $0,1 \mathrm{~g} / \mathrm{L}$ de $\mathrm{K}_{2} \mathrm{HPO}_{4}$. O pH da polpa foi medido (Equipamento Hanna HI931400), ajustado diariamente com adição de ácido sulfúrico concentrado (98\%) ou de $\mathrm{NaOH} 2,5 \mathrm{~mol} / \mathrm{L}$. O potencial de oxidação, medido em relação ao eletrodo $\mathrm{Ag} / \mathrm{AgCl}$, também foi medido diariamente (Equipamento Digimed DM20). Análises de níquel e ferro foram efetuadas, regularmente, pelo método de espectrofotometria de absorção atômica, em um Equipamento Perkim Elmer Modelo AAnalist100. 
Tabela 1 - Análise mineralógica e química do material utilizado.

\begin{tabular}{c|c|c|c|c|c|c}
\hline Parâmetro & Ni (\%) & Fe (\%) & Co (\%) & Cu (\%) & S (\%) & $\begin{array}{c}\text { Área Superficial } \\
\left(\mathbf{m}^{2} / \mathbf{g}\right)\end{array}$ \\
\hline $\begin{array}{c}\text { Pentlandita associada à pirrotita, } \\
\text { calcopirita, magnetita e a silicatos }\end{array}$ & 5,9 & 28,1 & 0,4 & 3,53 & 21 & 2,126 \\
\hline
\end{tabular}

\section{Resultados e discussão}

\subsection{Caracterização material}

Os resultados da caracterização do material estão apresentados na Tabela 1.

A caracterização ao microscópio ótico revelou diversos intercrescimentos entre os sulfetos presentes no concentrado, sobretudo entre pentlandita e pirrotita, apesar da granulometria fina do concentrado ( $80 \%$ menor que $47 \mu \mathrm{m})$. A partir dos resultados de composição química, pôde-se calcular a seguinte composição mineralógica da amostra: $40 \%$ pirrotita, $17 \%$ pentlandita e $0,3 \%$ calcopirita.

\subsection{Ensaios de biolixiviação do concentrado de flotação}

\section{Ensaio de suscetibilidade à biolixiviação}

Os primeiros ensaios foram realizados para verificar: (i) a suscetibilidade do concentrado de flotação de pentlandita à biolixiviação; (ii) a extensão da variação dos parâmetros pH, Eh, concentração de $\mathrm{Fe}(\mathrm{II})$ e $\mathrm{Fe}(\mathrm{III})$ durante a biolixiviação. A Figura 1 mostra a evolução do pH e do Eh, com o tempo, nesses ensaios, nos quais o pH foi apenas monitorado (não controlado). Pode-se observar que o $\mathrm{pH}$ varia fortemente durante a lixiviação bacteriana, pois ocorrem diferentes reações no sistema.

Pela Figura 1, pode-se observar que o $\mathrm{pH}$ aumenta durante as primeiras 70 horas de ensaio. Esse resultado é consistente com o obtido por Mason e Rice (2002), que observaram resultados semelhantes durante as primeiras 48 horas

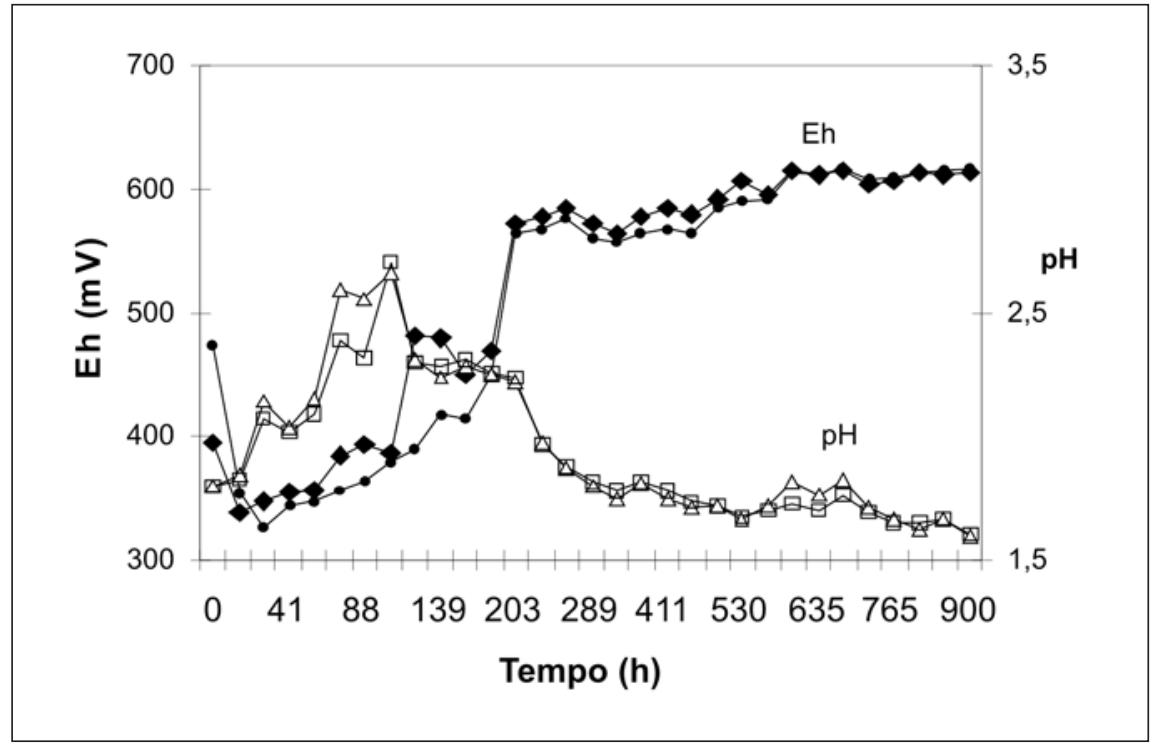

Figura 1 - Evolução do pH e do Eh, no ensaio de suscetibilidade à biolixiviação do concentrado de flotação de pentlandita. Ensaios realizados em duplicata; $\mathrm{pH}$ inicial 1,8; $34{ }^{\circ} \mathrm{C} ; 5 \%$ sólidos.

de experimento. Pode-se atribuir a diferença de duração da etapa inicial, observada nos dois trabalhos, às deferentes associações mineralógicas presentes nos concentrados estudados.

Mason e Rice (2002) também propuseram que a elevação do pH é a combinação de reações oxidativas e não oxidativas, devidas à dissolução dos sulfetos presentes. Os autores propuseram as equações 05 e 06 para a dissolução da pirrotita, que representa o sulfeto presente em maior proporção no concentrado do presente estudo. As reações 05 (dissolução ácida da pirrotita) e 06 (oxidação da pirrotita em presença de oxigênio) são consumidoras de ácido:

$\mathrm{Fe}_{1-x} \mathrm{~S}+2 \mathrm{H}^{+} \rightarrow(1-3 x) \mathrm{Fe}^{+2}+\mathrm{H}_{2} \mathrm{~S}$

$2 \mathrm{Fe}_{1-x} \mathrm{~S}+\mathrm{O}_{2}+4 \mathrm{H}^{+} \rightarrow(2-6 x) \mathrm{Fe}^{+2}+4 x \mathrm{Fe}^{+3}+2 \mathrm{~S}^{0}+2 \mathrm{H}_{2} \mathrm{O}$

Um aspecto importante das equações 05 e 06 é o fato de elas mostrarem a pirrotita se dissolvendo em meio ácido. A demanda de ácido na dissolução da pirrotita é $0.558 \mathrm{Kg} / \mathrm{Kg}$ de mineral e 0,413 Kg/Kg para a pentlandita, segundo Miller et al. (1997). Dessa forma, o consumo de ácido para a dissolução dos sulfetos explicaria a elevação inicial do pH. No presente trabalho, propõe-se que, apesar de os dois sulfetos (pirrotita e pentlandita) se dissolverem em ácido, a principal contribuição ao consumo de acidez é a dissolução da pirrotita.

Baixos valores de Eh observados nas primeiras 70 horas estão associados ao consumo de íons Fe(III), proveniente do inóculo, através da oxidação química dos 
sulfetos e do acúmulo de Fe(II), produzido pela dissolução ácida da pirrotita. A evolução da concentração de Fe(II) pode ser observada na Figura 2. Nessa Figura, pode-se observar que a concentração de Fe(II) eleva-se até cerca de 110 horas, o que ressalta a importância da dissolução ácida da pirrotita nessa fase do processo.

Associada ao consumo de acidez está a oxidação do Fe(II) via ação bacteriana (equação 3) (Garcia Jr., 1991). Na etapa inicial, essa reação possui pouca relevância, uma vez que pode-se associar essas primeiras horas de ensaio à fase lag de crescimento bacteriano. Desta forma, a equação 3 tem pouca influência no pH exibido no sistema até 110 horas (quando o Fe(II) começa a ser oxidado e o Eh cresce), sendo a reação de maior importância a dissolução ácida da pirro-

tita (eq. 5).

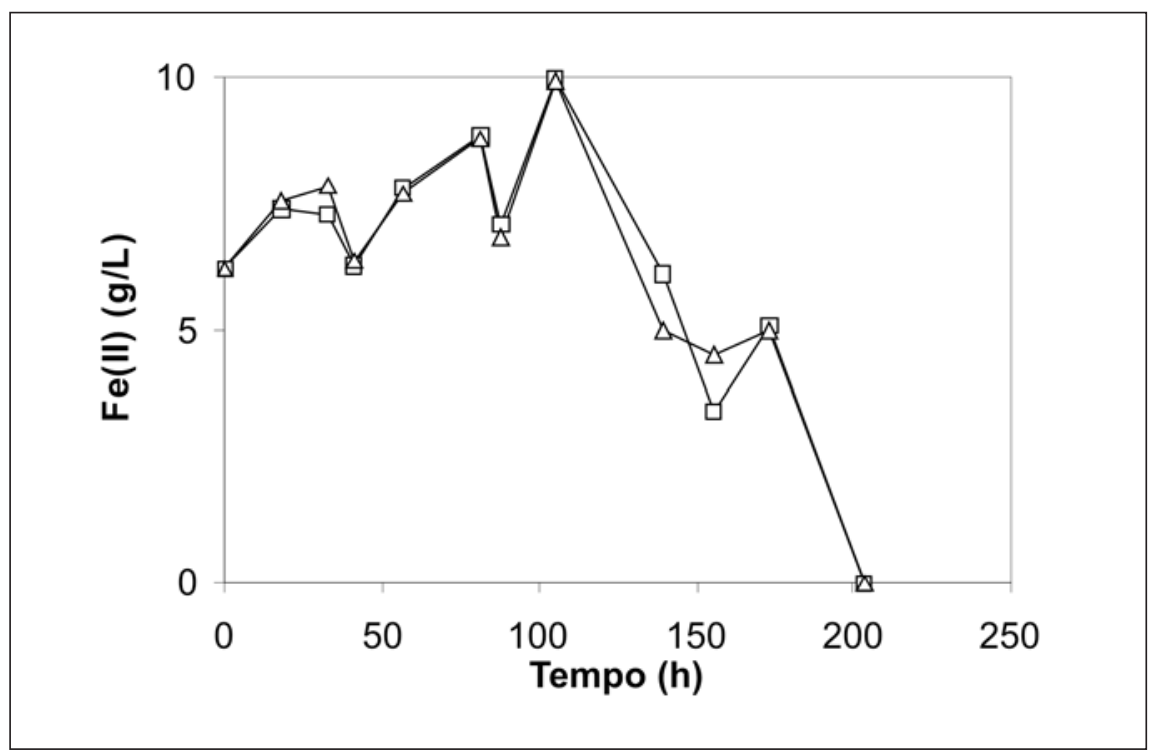

Figura 2 - Evolução da concentração de $F e(I I)$, no ensaio de suscetibilidade à biolixiviação do concentrado de flotação de pentlandita. Ensaios realizados em duplicata; $\mathrm{pH}$ inicial 1,$8 ; 34^{\circ} \mathrm{C} ; 5 \%$ sólidos.
Entre 110 e 150 horas, o potencial do sistema (Eh) se eleva, fenômeno associado à queda do $\mathrm{pH}$. Essa queda deve-se, principalmente, ao inicio da precipitação de Fe(III) como jarosita (Santos et al., 2006). Embora Mason e Rice (2002) tenham proposto que a precipitação de Fe(III) ocorre como diversos compostos básicos de Fe(III), no presente trabalho, foi identificada apenas a precipitação de jarosita (eq. 07) (Santos et al., 2006) de acordo com o observado na literatura (McIntosh \& Groat 1997). O pH exibido no sistema, no intervalo de 110 a 150 horas, é, então, a combinação das reações $3,5,6,7$, sendo algumas produtoras (eq. 07) e outras consumidoras de ácido (eq. 3, 5 e 6).

$$
\mathrm{X}^{+}+3 \mathrm{Fe}^{+3}+2 \mathrm{SO}_{4}^{-2}+6 \mathrm{H}_{2} \mathrm{O} \rightarrow \mathrm{XFe}_{3}\left(\mathrm{SO}_{4}\right)_{2}(\mathrm{OH})_{6}+6 \mathrm{H}^{+} ; \mathrm{X}=\mathrm{K}^{+}, \mathrm{Na}^{+}, \mathrm{NH}_{4}^{+} \mathrm{Ou} \mathrm{H}_{3} \mathrm{O}^{+}
$$

Outra reação produtora de ácido é a oxidação do enxofre elementar formado na superfície dos sulfetos (eq. 04). Essa reação passa a ter importância somente após 150 horas, quando cerca de $70 \%$ do ferro em solução está sob a forma de Fe(III). Isto ocorre porque os microorganismos tendem a utilizar, preferencialmente, o $\mathrm{Fe}(\mathrm{II})$ como fonte de energia (Rodríguez et al., 2001), ou seja, a biooxidação do enxofre elementar só ocorre após o consumo de Fe(II) do sistema.

Após 200 horas, quando todo o ferro está sob a forma de Fe(III) (Figura 2), intensifica-se a fase de produção de ácido, que agrega, além da reação de oxidação do enxofre elementar formado na superfície dos sulfetos (eq. 04), a precipitação de jarosita (eq. 07). As reações consumidoras de ácido possuem, agora, contribuição limitada, uma vez que praticamente toda a pirrotita do sistema foi solubilizada (Santos et al., 2006).

\section{Influência do pH}

Foram realizados ensaios para verificar o efeito do $\mathrm{pH}$ na extração de níquel. Nesses ensaios, as condições utilizadas foram: concentração inicial de Fe(II) igual a 2,5g/L e pH controlado nos valores: 1,6, 1,8, 2,0, 2,2, 2,4. A Figura 3 mostra a evolução do percentual de extração de níquel para diferentes valores de $\mathrm{pH}$.
Observando a Figura 3, percebe-se a influência da ação bacteriana, quando comparados os percentuais de extração de níquel nos ensaios de biolixiviação e no controle. Um fator importante a ser observado nessa série de experimentos é que maiores percentuais de extração de níquel não estão ligados a maior acidez, ou seja, a pentlandita não é dissolvida pela acidez do sistema na ausência de Fe(III) (Schippers \& Sand, 1999). O mesmo não ocorre com a pirrotita. No sistema estudado, observou-se que maiores concentração de Fe(II) estavam associadas a menores valores de $\mathrm{pH}$, o que permite inferir a influência do $\mathrm{pH}$ na dissolução desse sulfeto em meio ácido (Schippers \& Sand, 1999).

A Figura 4 mostra a variação da concentração de Fe(II) e de ferro total com o tempo no sistema para diferentes valores de $\mathrm{pH}$ inicial. Observa-se, pela Figura 4A, que a oxidação do $\mathrm{Fe}(\mathrm{II})$ a $\mathrm{Fe}(\mathrm{III})$ ocorre mais rapidamente para valores maiores de $\mathrm{pH}$ (Figura 4A) e que, logo após todo o $\mathrm{Fe}(\mathrm{II})$ ser convertido a $\mathrm{Fe}(\mathrm{III})$, inicia-se a precipitação (como jarosita) desse íon (Figura 4B). Observase, também, que, precipitação é mais rápida para maiores valores de $\mathrm{pH}$. A precipitação de jarosita poderia levar ao recobrimento das partículas de pentlandita, e impediria o ataque do agente oxi- 
dante (Fe(III)), diminuindo a velocidade de dissolução do Ni e a contribuição do mecanismo indireto (Santos et al., 2006). Mas, como a diferença de tempo de nucleação e precipitação da jarosita para diferentes valores de $\mathrm{pH}$ é pequena, quando comparada ao tempo total de biolixiviação, acredita-se que esse fenômeno apresente pequena influência na extração do metal (Figura 3), excetuandose o experimento conduzido no $\mathrm{pH}$ 2,4.

Rodriguez et al. (2001) sugeriram que microorganismos do gênero Acidithiobacillus $s p$. utilizam, preferencialmente, o Fe(II) ao enxofre, como fonte de energia, e que maiores quantidades de $\mathrm{Fe}(\mathrm{II})$ iniciais produzem, maiores percentuais de extração via mecanismo indireto, desde que a camada de enxofre não impeça a oxidação do sulfeto, ou, em outras palavras, desde que bactérias capazes de remover a camada de enxofre estejam presentes. Apesar disto, mesmo que maior quantidade de $\mathrm{Fe}(\mathrm{II})$ seja solubilizada em menor $\mathrm{pH}$, como discutido anteriormente, a oxidação e a precipitação do ferro ocorrem muito rapidamente (Figura 4A e 4B). Isto impede que haja contribuição significativa do mecanismo indireto na biolixiviação do concentrado. Baseado nesse fato, sugere-se que o mecanismo predominate de biolixivação desse sulfeto misto seja o mecanismo direto, como proposto por Zhang e Fang (2005).

Concluindo, a variável pH apresenta um valor ótimo para a extração de níquel, em torno de 2,0. A baixa dissolução em $\mathrm{pH}$ 2,4 parece estar ligada, basicamente, à precipitação da jarosita, que recobre as partículas de sulfeto e remove microrganismos do meio (Donati \& Poligani, 2000), reduzindo a dissolução do metal. Por outro lado, condições de pH abaixo de 1,8 desfavorecem o crescimento do microrganismo e, por conseguinte a dissolução do sulfeto.

\section{Influência da densidade de polpa}

Foram realizados ensaios para verificar o efeito da densidade de polpa sobre o percentual de extração de níquel. Nesses ensaios, as condições utilizadas foram: concentração inicial de Fe(II) igual

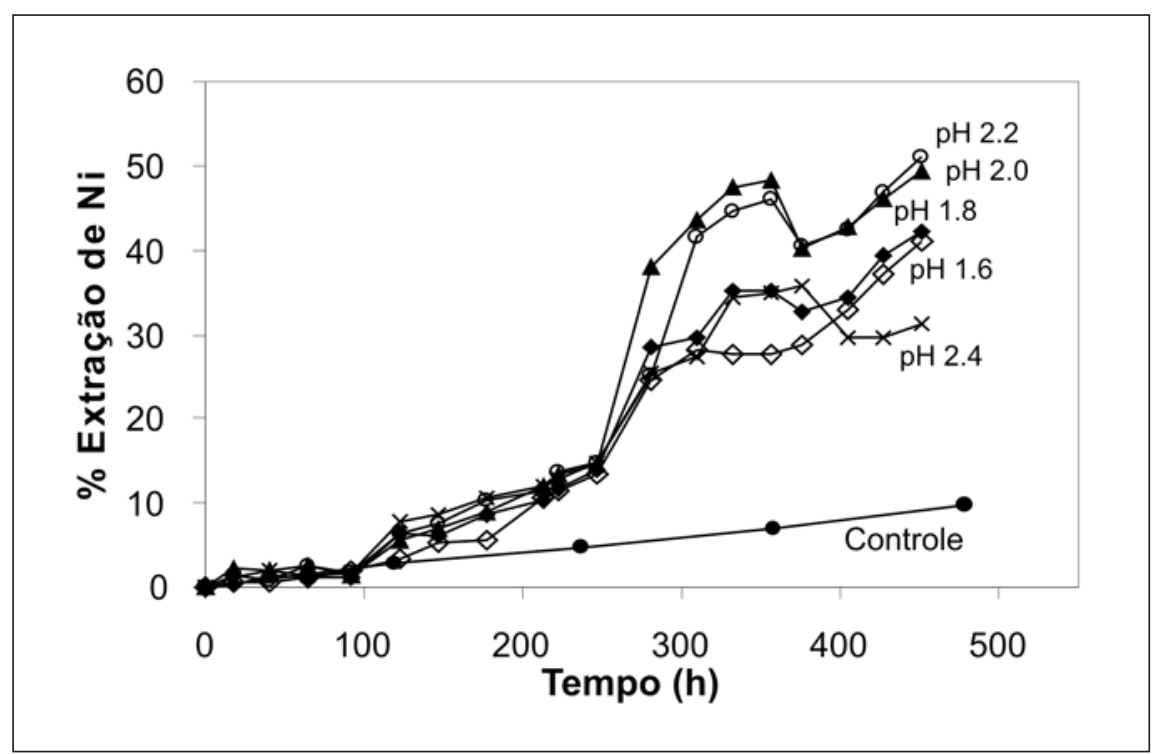

Figura 3 - Evolução do percentual de extração de níquel nos ensaios da influência do pH na biolixiviação do concentrado de flotação de pentlandita. Concentração inicial de $\mathrm{Fe}(\mathrm{II})$ igual a $2,5 \mathrm{~g} / \mathrm{L}, 34^{\circ} \mathrm{C}, 5 \%$ sólidos.

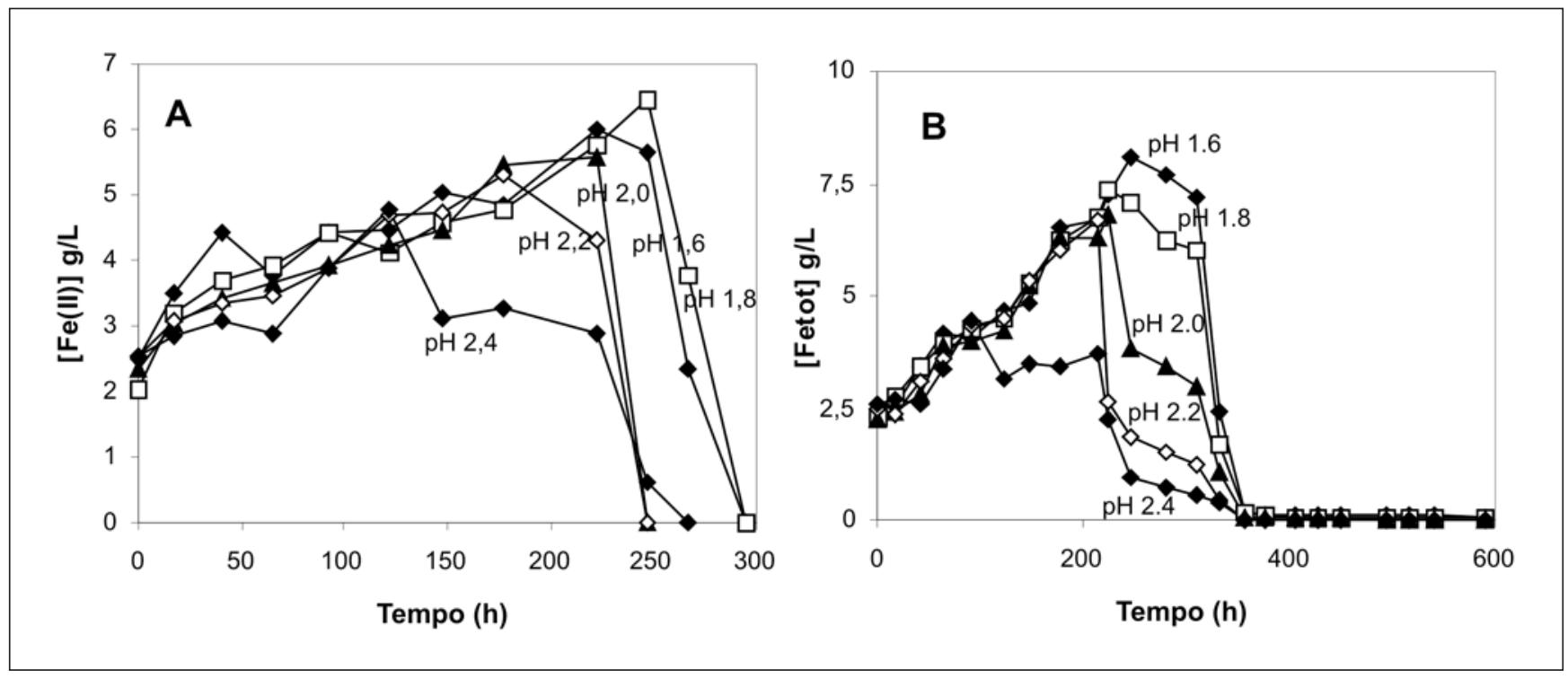

Figura 4 - Evolução da concentração de ferro(II) (A) e da concentração de ferro total (B) nos ensaios da influência do pH na biolixiviação do concentrado de flotação de pentlandita. Concentração inicial de $\mathrm{Fe}(\mathrm{II})$ igual a $2,5 \mathrm{~g} / \mathrm{L} ; 34{ }^{\circ} \mathrm{C} ; 5 \%$ sólidos. 


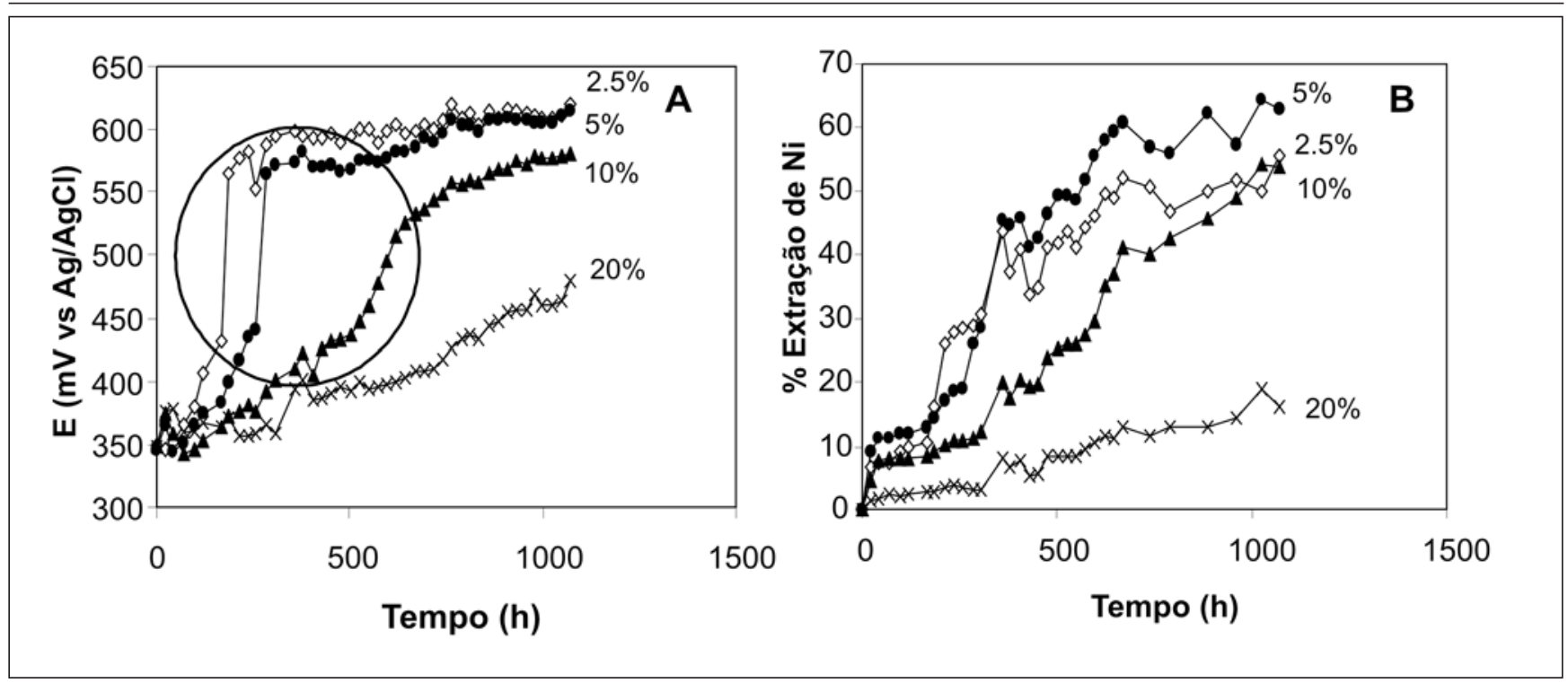

Figura 5 - Evolução do Eh (A) e do percentual de extração de níquel (B) nos ensaios de influência da densidade de polpa na biolixiviação do concentrado de flotação de pentlandita. Concentração inicial de $\mathrm{Fe}(\mathrm{II})$ igual a $5 \mathrm{~g} / \mathrm{L} ; 34^{\circ} \mathrm{C} ; \mathrm{pH} 1,8$. O círculo indica a fase de crescimento exponencial.

a $5 \mathrm{~g} / \mathrm{L}$, pH igual a 1,8 e densidades de polpa iguais a $2,5 \%, 5 \%, 10 \%$ e $20 \%$. A Figura 5 mostra a evolução do Eh e do percentual de extração para essa série de experimentos. Observa -se que o Eh (Figura 5A) aumenta mais rapidamente para menores percentuais de sólidos. Isto está associado ao fato de que, para maiores percentuais de sólidos, as concentrações de íons Fe(II) em solução são maiores, uma vez que maiores quantidades de sulfeto são solubilizadas, como mostra a Figura 6. Considerando que nos sisitemas de biolixiviação o Eh é determinado basicamente pela relação $\mathrm{Fe}^{+2} / \mathrm{Fe}^{+3}$, a maior concentração de $\mathrm{Fe}$ (II) obtido a $20 \%$ de sólidos reduz o valor do potencial do sistema.

Pode-se, ainda, observar, na Figura $5 \mathrm{~A}$, uma região de crescimento exponencial, para os ensaios conduzidos com 2,5\%, 5,0\% e 10,0\% de sólidos (em destaque). Esse comportamento indica a adaptação da bactéria ao meio em questão. Para o ensaio contendo 20\% sólidos, não se observa a fase de crescimento exponencial, o que indica que o microorganismo não se adaptou a essta condição. Dessa forma, menores percentuais de extração são observados para o ensaio conduzido com $20 \%$ de sólidos

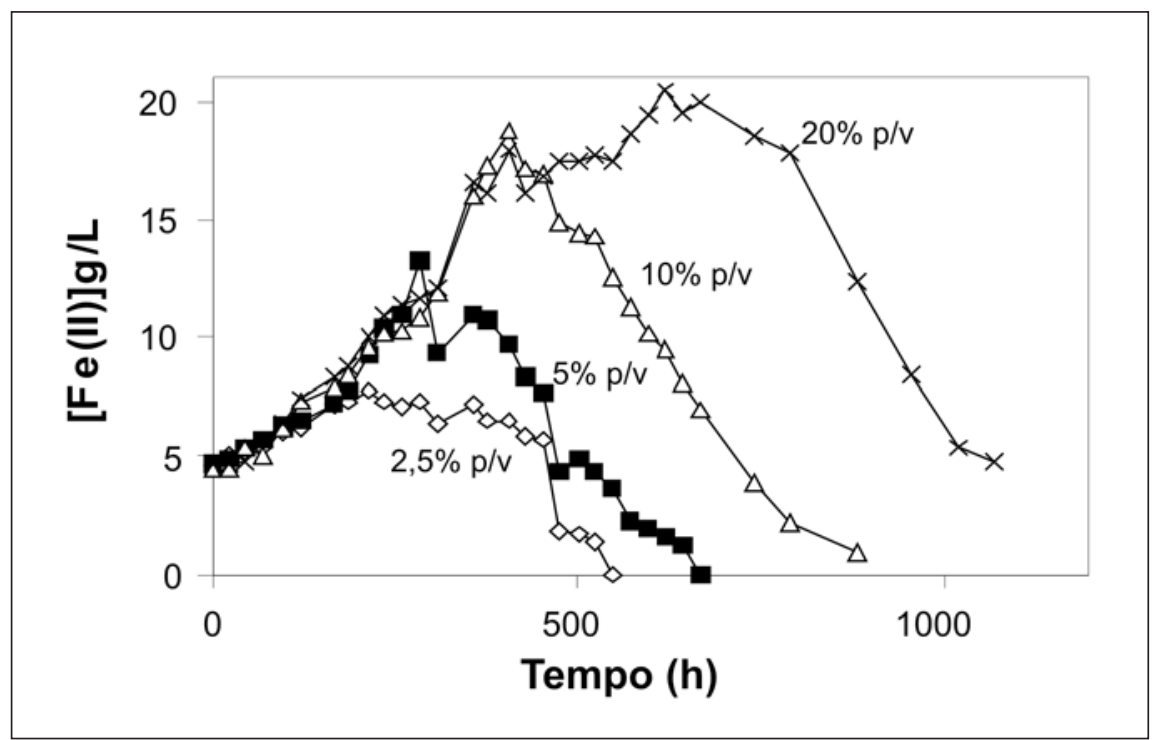

Figura 6 - Evolução da concentração de ferro total nos ensaios de influência da densidade de polpa na biolixiviação do concentrado de flotação de pentlandita. Concentração inicial de $\mathrm{Fe}(\mathrm{II})$ igual a $5 \mathrm{~g} / \mathrm{L} ; 34^{\circ} \mathrm{C}$; $\mathrm{pH} 1,8$.

(Figura 5B). Pela Figura 5B, observase, também, que os percentuais de extração, compreendidos entre $2,5 \%$ a $10 \%$ de sólidos, apresentam evolução semelhante. Isto se deve ao baixo teor de material sulfetado presente no concentrado (21,2\% de enxofre), que faz com que, mesmo em percentuais de polpa próximos a $10 \%$ de sólidos, a quantidade de substrato a ser oxidado não seja excessiva.
A baixa extração de metais em elevados percentuais de sólido (20\%) é atribuída à redução da transferência de massa dos gases necessários à biolixiviação $\left(\mathrm{CO}_{2}\right.$ e $\left.\mathrm{O}_{2}\right)$. Para verificar essa hipótese, um experimento de oxidação de $\mathrm{Fe}(\mathrm{II})$ foi realizado na presença e ausência de $20 \%$ de material inerte (100\% $<63 \mu \mathrm{m})$. A Figura 7 mostra os resultados desse experimento. 
Pela Figura 7, pode-se observar que, na presença de $20 \%$ de sólidos, o tempo de biooxidação dos íons Fe(II) aumenta em cerca de 13 horas. Esse fato indica que a presença de elevado percentual de sólidos realmente dificulta a transferência gasosa no sistema (Boon, 2001b). Porém, no presente trabalho, considerase que essa diferença de 13 horas entre os dois sistemas seja pouco relevante. Embora a transferência de massa dos gases $\left(\mathrm{CO}_{2}\right.$ e $\left.\mathrm{O}_{2}\right)$ pareça não afetar, significativamente, a biooxidação de Fe(II), em sistemas batelada, o crescimento bacteriano é controlado pela solubilidade do dióxido de carbono no meio (Witne \& Phillips, 2001). Desta forma, no ensaio a 20\% de sólidos, as baixas extrações são, provavelmente, devidas ao crescimento da população bacteriana, limitado pela concentração de $\mathrm{CO}_{2}$ disponível. Em outras palavras, existe maior quantidade de metal para ser oxidado nos ensaios com maior percentual de sólidos (Figura 6), sendo que as extrações são mais baixas, pois o $\mathrm{CO}_{2}$ controla o crescimento bacteriano e, por conseguinte, a oxidação do sulfeto.

\section{Conclusões}

A biolixiviação pode ser uma alternativa viável para a rápida oxidação de sulfetos complexos de ferro e níquel com forma de se reduzir a geração de DAM. Percentuais de extração de até $60 \%$ foram obtidos nos ensaios realizados. $\mathrm{O}$ $\mathrm{pH}$ possui pequena influência nos percentuais de extração obtidos, sendo o valor ideal em torno de 2,0. Sua influência parece estar ligada, principalmente, ao controle da formação de jarosita, que, por sua vez, interfere na população bacteriana, que é removida do sistema por adesão à jarosita. Percentuais de sólidos de até $10 \%$ podem ser praticados, sem apresentarem diferenças significativas sobre a extração de níquel. Os resultados encontrados sugerem que a presença de elevados teores de sólidos compromete pouco a transferência gasosa, sendo a biolixiviação do sulfeto controlada pela disponibilidade de dióxido de carbono no sistema.

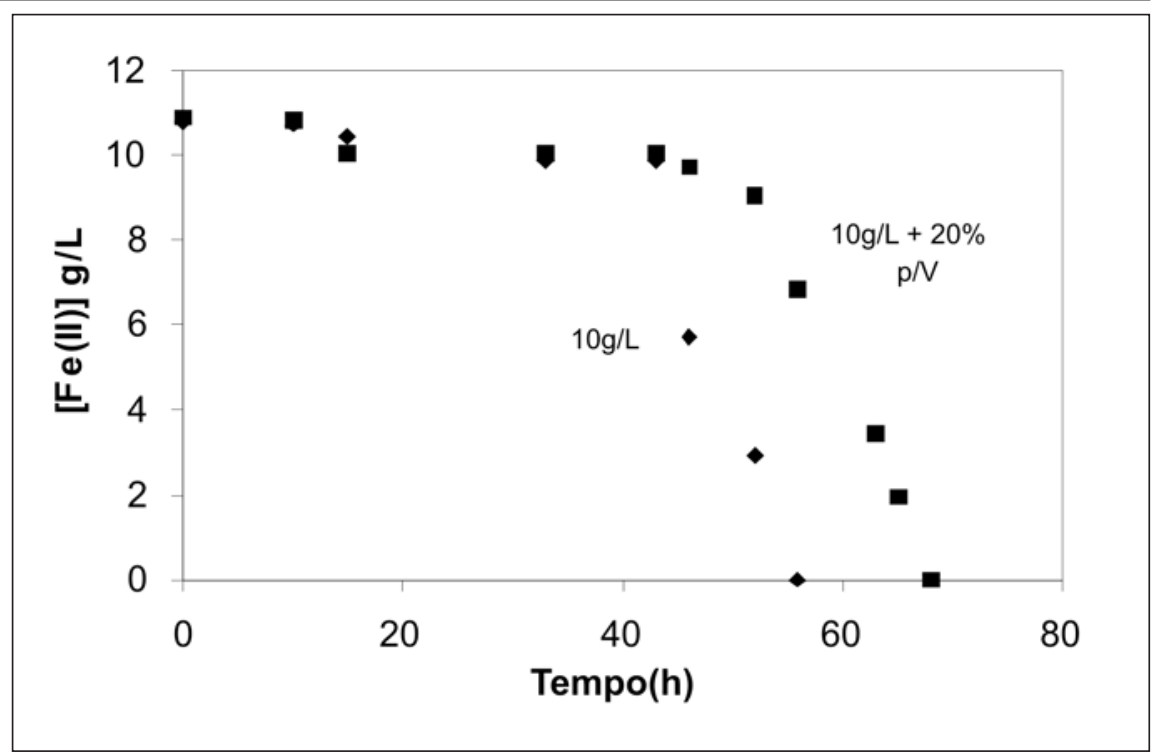

Figura 7 - Evolução da concentração de Fe(II) nos ensaios de biooxidação na presença e na ausência de elevado percentual de sólido inerte $(20 \%$ areia $100 \%<63 \mu \mathrm{m})$. Concentração inicial de Fe(II) igual a $10 \mathrm{~g} / \mathrm{L} ; 34^{\circ} \mathrm{C}$; pH 1,8 .

\section{Agradecimentos}

Os autores agradecem à FINEP e à Votorantim Metais e FAPEMIG, pelo financiamento; Ao CNPq pela bolsa de Mestrado de Luciano Rodrigo Gomes Santos e ao Departamento de Metalurgia da UFMG, pelas análises de enxofre.

\section{Referências bibliográficas}

BOON, M. Theoretical and experimental methods in the modelling of biooxidation kinetics of sulphide minerals. Delft. Technishe Universiteit Delft. 2001. 442 p. (PhD Thesis).

DAMAN, D., LEÃO, V. A., SILVA, C. A., GOMES, F. J. Biooxidação de esfalerita brasileira por Acidithiobacills sp. In: ENCONTRO NACIONAL DE TRATAMENTO DE MINÉRIOS E METALURGIA EXTRATIVA, 19. BALTAR, C. A. M., OLIVEIRA, J. C. S. , BARBOSA, J. P. (eds.). Anais... Recife, Brasil. 2002, v. 02, p. 76-82.

DONATI, E., POLIGANI, C. Immobilisation of Thiobacillus ferrooxidans : importance of jarosite precipitation. Process Biochemistry, v. 35, n. 2, p. 997-1004, 2000.

FOWLER, T. A., CRUNDWELL, F. K. Leaching of zinc sulphide by Thiobacillus ferrooxidans: Bacterial oxidation of the sulphur product layer increases the rate of zinc sulphide dissolution at high concentrations of ferrous iron. Applied and Environmental Microbiology, v. 65, n. 12, p. 5285-5292, 1999a.

FOWLER, T. A., CRUNDWELL, K. K. The role of Thiobacills ferrooxidans in the bacterial leaching of zinc sulphide. In: biohydrometallurgy and environmental towards the mine of the 21st Century. AMILS, R., BALLESTER, A. (eds.), 1999b. Madri, Spain. Anais..., Elsevier. 1999b, v. 01, p. 273-281.

GARCIA Jr., O. Lixiviação de metais por bactérias. Centro de Tecnologia Mineral (CETEM), 1991.

GÓMEZ, E., BLÁZQUEZ, M. L. e BALLESTER,A. Bioleaching of a spanish complex sulphide ore bulk concentrate. Minerals Engineering, v. 12, p. 93-106, 1999.

LACEY, D. T., LAWSON, F. Kinetics of the liquid-phase oxidation of acid ferrous sulfate by the bacterium thiobacillus ferooxidans. Biotechnology and Bioengineering, v. 12, p. 29-50, 1970.

MASON, L. J., RICE, N. M. The adaptation of Thiobacillus ferrooxidans for the treatment of nickel-iron suphide concentrates. Minerals Engineering, v.15, p. 795-808, 2002.

MCINTOSH, J. M., GROAT, L. A. Biological-mineralogical interactions. Mineralogical association of Canada, Short course series. Ottawa. 1997. 
